\title{
A study of prevalence of anisometropia and associated amblyopia in patients with refractive error
}

\author{
Singh $\mathbf{P}^{1}$, Kumar $\mathbf{R}^{2}$, Gontia $\mathbf{J}^{3}$, Singh DP ${ }^{4}$, Gupta $\mathrm{SB}^{5}$ \\ Dr Priti Singh, Assistant professor, Department of Ophthalmology, Dr Rashmi Kumar, Assistant professor, Department \\ of Ophthalmology, Dr Jyoti Gontia, Intern, Dr Devendra Pratap Singh, Associate professor medicine, Dr S B Gupta, \\ Professor of ophthalmology. All are affiliated with L N Medical College, Bhopal, MP, India
}

Address for correspondence: Dr Priti Singh, Email: singh_priti2178@yahoo.com

\begin{abstract}
Aims: The present study was planned to evaluate the prevalence of anisometropia in patients with refractive error, to compare the prevalence of different types of anisometropia and to study the prevalence of amblyopia in anisometropic patients. Material and Method: It was a cross sectional study in which 400 randomly selected patients were evaluated for anisometropia and also for anisometropic amblyopia. All patients underwent thorough ophthalmic examination including visual acuity testing, slit lamp examination and fundus examination. Later on the data was analysed statistically with different formulas like Chi square test, Fisher exact test etc. Results: The prevalence of anisometropia was found to be $16.5 \%$ in total 400 patients with refractive errors, out of which $57.5 \%$ were females and $42.5 \%$ were male patients. Prevalence was found maximum in 20-30 years age group (36.4\%). Highest prevalence among various types of anisometropia was found of compound myopic anisometropia (37.9\%). Conclusion: No gender difference was seen in prevalence of anisometropia. Prevalence of anisometropia significantly varied with different age groups. The prevalence of amblyopia in patients of anisometropia was found to be statistically significant ( $p$ value=.0001).
\end{abstract}

Key words: Anisometropia, Amblyopia, Refractive Error.

\section{Introduction}

Anisometropia is a condition when the total refraction of two eyes is unequal [1]. A difference of $1 \mathrm{D}$ in two eyes causes $2 \%$ difference in size of two retinal images [1]. In other words, an anisometropia up to $2.5 \mathrm{D}$ is well tolerated and that between 2.5 and $4 \mathrm{D}$ can be tolerated depending upon the individual sensitivity. However, more than 4D will not be tolerated and is a matter of concern [2].

The exact prevalence of anisometropia is not known in general population; a prevalence of $4-4.7 \%$ has been described in literature [3].

The prevalence and severity of anisometropia increases significantly with increasing age and peaks at around 50 years then it decreases with further advancement in age. In females prevalence was found to be higher then male patients. Prevalence in females was $19.9 \%$ versus $16.6 \%$ in male patients, which was statistically

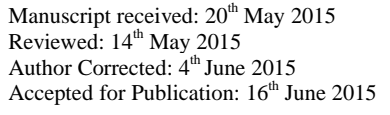

significant [4].

Authors found that the presence of myopia, age, and sex were all independent risk factors associated with anisometropia [4]. Since anisometropia is a major cause of amblyopia therefore, those patient of refractive error having anisometropia need to be evaluated for the presence of amblyopia, especially in children.

Amblyopia refers to partial loss of vision in one or both eyes, in the absence of any organic disease of ocular media, retina and visual pathway [1]. Anisometropic amblyopia occurs in an eye having higher degree of refractive error than the fellow eye. It is more common in aniso-hypermetropic than the aniso-myopic children. Even 1-2 D hypermetropic anisometropia may cause amblyopia with up to 3D myopic anisometropia usually does not cause amblyopia [1].

According to a study, the total number of patients with amblyopia were $2.67 \%$. There were $56.25 \%$ of these cases presenting anisometropic amblyopia. Prevalence 
of amblyopia and anisometropia in men and women were not different. The prevalence of anisometropia in men and women was $48.44 \%$ and $51.56 \%$ respectively $[5]$.

In a population based study on anisometropia, prevalence of anisometropia was $17 \%$ [6]. The odds showed significant increase in anisometropia every year by $2.8 \%$. Prevalence is more in older patient but children should be considered due to risk of amblyopia [6].

In another study, prevalence of anisometropia on subjective analysis and cycloplegic refraction was $18.5 \%$ and $19.3 \%$ respectively. In hypermetropes analysis revealed that only spherical refractive error and age were independently associated with anisometropia. In myopes all explanatory variables were independently associated with anisometropia. Female sex was closely associated with anisometropia [4].

In a population based study of Tehran Iran, prevalence of anisometropia is beyond negligible. It showed a significant increase with age. Results also indicate that myopic patients are more likely to have anisometropia [7]. In one more study, prevalence of amblyopia in older patients was $2.6 \%$. Underlying cause was anisometropia in $50 \%$ patients of amblyopia [8].

In the present study, we tried to find out the prevalence of anisometropia in patients with refractive error and also of associated amblyopia. It simply describes the prevalence of anisometropia in refractive error patients and emphasize on correction of anisometropia for prevention of amblyopia.

\section{Aims}

Aims of study are:

1. To determine the prevalence of anisometropia in patients with refractive error.

2. To compare the prevalence of different types of anisometropia.

3. To study the prevalence of amblyopia in anisometropic patients.

\section{Material and Method}

It was an institution based cross sectional study. The sample population was randomly selected 400 patients with refractive error. Selection was done randomly.
Both male and female, wearing or not wearing glasses were taken into account

This study was done in patients visiting Ophthalmology out patients department of our institute between August and September of 2014 with refractive error and then in them by estimation of refractive error, anisometropia was known. Further we classified the available data according to types of anisometropia, age groups and sex.

Clinical types of anisometropia are [2]:-

1. Simple anisometropia: - one eye is emetropic and other myopic or hypermetropic.

a. Simple myopic anisometropia

b. Simple hypermetropic anisometropia.

2. Compound anisometropia- both eyes either myopic or hypermetropic

b. Compound myopic anisometropia

c. Compound hypermetropic anisometropia

3. Mixed anisometropia: - one eye myopic and other hypermetropic.

4. Simple astigmatic anisometropia: - one eye normal and other myopic or hypermetropic astigmatism.

5. Compound astigmatic anisometropia: - when both eyes are astigmatic but of unequal degree.

A predesigned and pretested proforma was used for data collection.

Snellen's chart was be used for distant vision.(Subject were evaluated by asking to sit in a room with sufficient light and read the Snellen's vision box from $6 \mathrm{~m}$ distance). Landolt's C-chart was used for illiterate patients. Roman test types were used for the testing of near vision.

Refractive testing was done by portable autorefractometer and streak retinoscope. Ophthalmoscopy and detailed slit lamp examination was done to rule out any other causes of low vision.

We also took into consideration the amblyopia caused due to anisometropia. Thus best corrected visual acuity of both the eyes was noted down separately. After data collection, we analyzed it by using various required statistical methods like percentage, proportions, graphs and tables, according to type of anisometropia. Statistical formulas used were prevalence, Chi - square test and Fisher Exact test. 


\section{Results}

- Out of 400 refractive error patients, 66 were present with anisometropia and the prevalence was $16.5 \%$.

- Out of total 66 anisometropic patients, 38 were females and 28 were males, gender wise difference of prevalence is: $57.5 \%$ and $42.5 \%$ respectively.

* We have classified the data according to different types of anisometropia. Prevalence of compound myopic anisometropia was found to be maximum (37.9\%) followed by compound astigmatic anisometropia (30.3\%) and is least of mixed anisometropia. (Table 1).

Table 1: Prevalence of different types of anisometropia

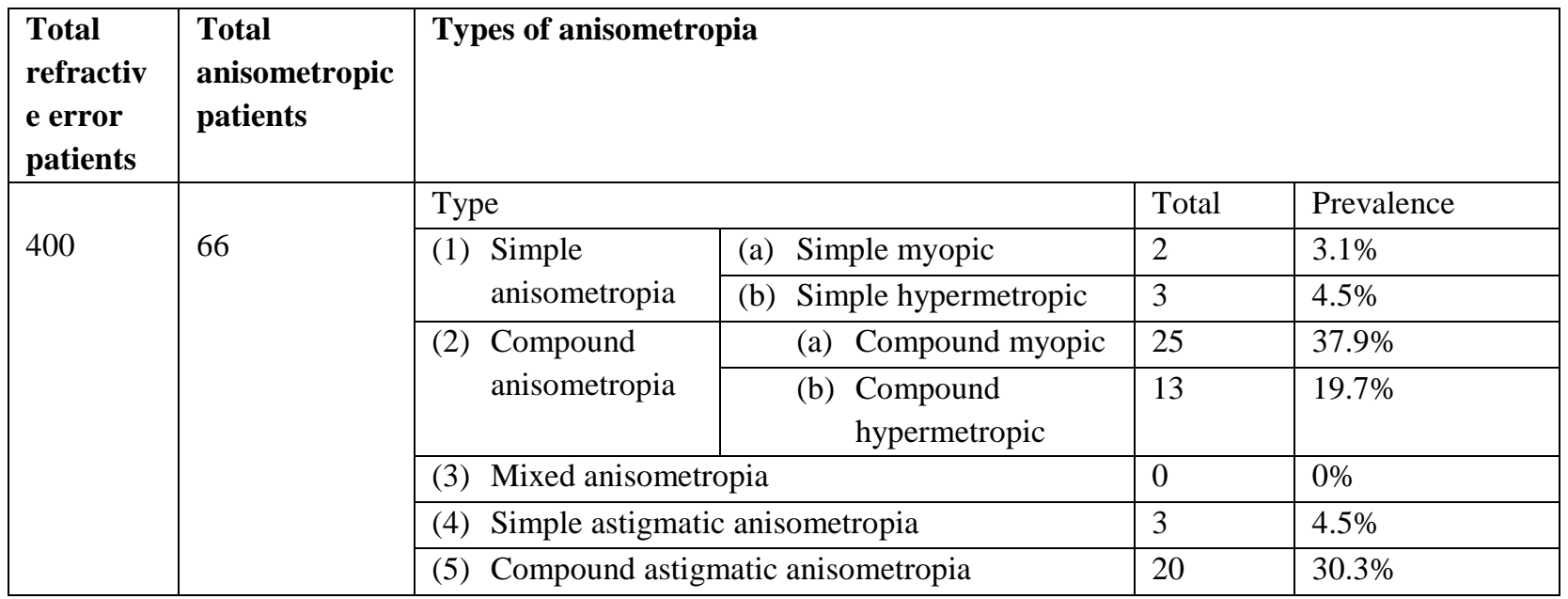

- Prevalence of anisometropia according to different age groups was shown in table 2. Prevalence of anisometropia varied significantly in different age groups. Maximum prevalence was found in the age group 20-30 (36.4\%) and minimum in age group 1-10 (4.5\%). This shows that as the age increases, the prevalence of anisometropia increases till third decade, and then again there occurs a declining trend.

$* \mathrm{x}^{2}=11.129, \mathrm{p}$ value $=.0488$ and it is statistically significant.

Table 2: Table showing prevalence of anisometropia in different age group patients

\begin{tabular}{|l|l|l|l|l|}
\hline S. No. & $\begin{array}{l}\text { Age Group } \text { ( in } \\
\text { years) }\end{array}$ & $\begin{array}{l}\text { Total Refractive } \\
\text { Error Patients (400) }\end{array}$ & Total Anisometropic Patients* (66) & $\begin{array}{l}\text { Percentage of } \\
\text { Aniso. Patients }\end{array}$ \\
\hline 1 & $1-10$ & 34 & 3 & $4.5 \%$ \\
\hline 2 & $10-20$ & 62 & 15 & $22.7 \%$ \\
\hline 3 & $20-30$ & 102 & 24 & $36.4 \%$ \\
\hline 4 & $30-40$ & 93 & 11 & $16.7 \%$ \\
\hline 5 & $40-50$ & 68 & 9 & $13.6 \%$ \\
\hline 6 & $50-60$ & 41 & 4 & $6.1 \%$ \\
\hline
\end{tabular}

$* x^{2}=11.129, p$ value $=.0488$ and it is statistically significant 
Figure 2: Figure showing prevalence of anisometropia in different age groups in percentage

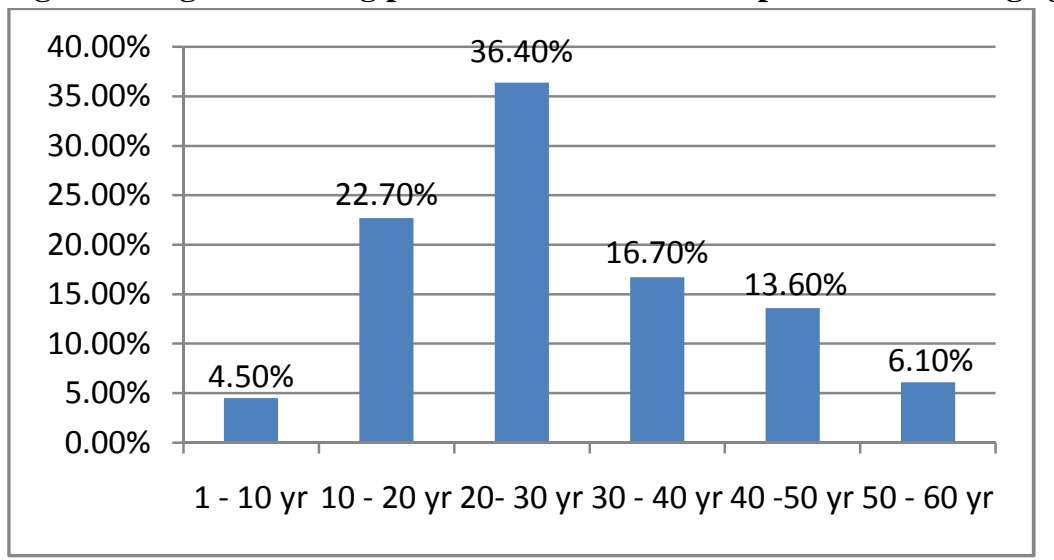

* Prevalence of anisometropic amblyopia in anisometropic patients is $1.25 \%$ ( table 3 and figure 3 )

$* \mathrm{p}$ value $=.0001$, which is statistically significant. (using Fisher Exact Test)

Table 3: Table showing anisometropic amblyopia prevalence

\begin{tabular}{|l|l|l|l|}
\hline $\begin{array}{l}\text { Total refractive error } \\
\text { patients }\end{array}$ & Total anisometropia patients & Total amblyopia patients* & $\begin{array}{l}\text { Prevalence of } \\
\text { amblyopia }\end{array}$ \\
\hline 400 & 66 & 5 & $1.25 \%$ \\
\hline
\end{tabular}

$* \mathrm{p}$ value $=.0001$, which is statistically significant. (Using Fisher Exact Test)

Figure 3: pie chart showing prevalence of anisometropic amblyopia patients

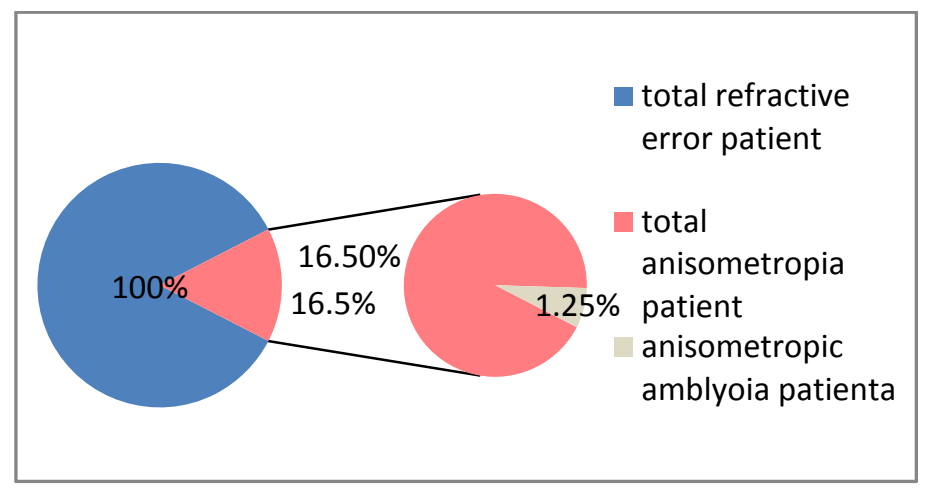

\section{Discussion}

Refractive errors are responsible for more than half of the impaired vision in the majority of surveyed population $[9,10]$. They affect a large proportion of the population worldwide, irrespective of age, sex, or ethnic group. They can be easily diagnosed, measured, and corrected and with spectacles and other refractive corrections to obtain normal vision. Unless corrected they cause low vision and even blindness $[9,11,12]$. The prevalence of refractive errors varies according to gender [10,12], age [10,12], educational level and amount of near work [13].
The majority of human ametropes can be characterised as isoametropic, in that the refractive status of their two eyes is very similar. In a minority of humans, however, there are significant interocular differences in refractive error (anisometropia), which can be accompanied by an interocular difference in visual acuity that is optically uncorrectable, at least initially (amblyopia). The cooccurrence of these two anomalies, with no additional abnormality, is labelled 'anisometropic amblyopia'. Anisometropia, therefore, is a special case of an emmetropization failure that is commonly accompanied by a serious neurological deficit [14]. 
In current study the prevalence of anisometropia is $16.5 \%$, which corresponds to a population based study on anisometropia in Mashhad, Iran where Prevalence of anisometropia was $17 \%$ [6].

Similarly, it also approximately corresponds to a study where prevalence of anisometropia on subjective analysis and cycloplegic refraction was $18.5 \%$ and $19.3 \%$ respectively [4].

As in our study we found out that female sex has close association with anisometropia as compared to male sex which was $57.5 \%$ and $42.5 \%$ respectively, similar results were found in a study where the prevalence of anisometropia in men and women was $48.44 \%$ and $51.56 \%$ respectively [5]. Another study says that female sex was closely associated with anisometropia [4] which is close to our result.

In this study different types of anisometropia (table 1) showed that prevalence is more in myopia and astigmatism patients. Results indicate that myopic patients are more likely to have anisometropia [7].

Lastly, the complication of anisometropia which is amblyopia, in our study was $1.25 \%$, on comparing with a previous study that says that prevalence of amblyopia in older patients was $2.6 \%$.

\section{Conclusion}

Thus our study concludes that the prevalence of anisometropia in males and females on comparing was found to be statistically insignificant. Similarly, when compared according to different age groups was found statistically significant, as change in prevalence is seen in different age groups. Lastly, complication of anisometropia i.e. amblyopia was found to be statistically significant, as anisometropia is one of the major cause of amblyopia.

\section{Funding: Nil}

Conflict of interest: Nil

Permission from Institutional Research Board (IRB): Yes

\section{Reference}

1. Sihota R, Tandon R . Refractive errors of the eye . In: Sihota R , Tandon R, editors. Parson's Diseases Of The Eye, $21^{\text {st }}$ ed. New Delhi: Elsevier ; 2011.p.79.
2. Khurana A K , Khurana B .Optics and Refraction .In: Khurana A K , editor. Comprehensive ophthalmology, $5^{\text {th }}$ ed. New Delhi:New age international (p)limited publishers.;2012.p.38.

3. de Vries J. Anisometropia in children: analysis of hospital population. $\mathrm{Br} \quad \mathrm{J}$ Ophthalmol. 1985 Jul;69(7):504-7.

4. Linke S J , Richard G , and Katz T. Prevalence and Associations of Anisometropia with Spherical Ametropia, Cylindrical Power, Age, and Sex in Refractive Surgery candidates.invest.ophthalmol.vis.sci..

2011;52(10):7538-7547

5. Mohsen A, Mohammad G B, Mohammad A A, Mehdi T S. Prevalence of strabismic binocular anomalies, amblyopia and anisometropia. J optom.2011;4(3):110-114.

6. Ostadimoghaddam H, Fotouhi A, Hashemi H, Yekta A A , Heravian J, Hemmati B et al .Prevalence of anisometropia in population based study. Strabismus.2012, dec;20(4):152-7.

7. Hashemi H, Khabazkhoob M , Yekta A , Mohammad K , Fotouhi A.Prevalence and Risk factors for anisometropia in the Tehran eye study Iran . Opthalmic Epidemiol. 2011 jun,18(3):122-8.

8. Attebo K, Mitchell P, Cumming R , Smith W, Jolly $\mathrm{N}$, Sparkes R . Prevalence and causes of amblyopia in an adult population. Ophthalmology. 1998 Jan;105(1):154-9.

9. He M, Zeng J, Liu Y, Xu J, Pokharel GP, Ellwein LB. Refractive error and visual impairment in urban children in southern China. Invest Ophthalmol Vis Sci. 2004;45:793-799.

10. Goh PP, Abquariyah Y, Pokharel GP, Ellwein LB. Refractive error and visual impairment in school-age children in Gombak District, Malaysia. Ophthalmology. 2005;112:678-685.

11. Resnikoff S, Pascolini D, Mariotti SP, Pokharel GP. Global magnitude of visual impairment caused by uncorrected refractive errors in 2004. Bull World Health Organ. 2008;86:63-70. 
12. Zhao J, Mao J, Luo R, Li F, Munoz SR, Ellwein LB. The progression of refractive error in school-age children: Shunyi district, China. Am J Ophthalmol. 2002; 134:735-743.

13. Wedner SH, Ross DA, Todd J, Anemona A, Balira $\mathrm{R}$, Foster A. Myopia in secondary school students in
Mwanza City, Tanzania: the need for a national screening programme. Br J Ophthalmol. 2002;86:12001206.

14. Barrett B T, Bradley A, Candy $\mathrm{T} R$. The Relationship between Anisometropia and Amblyopia . Preg Retin Eye Res . 2013 september; 36:120-158.

\section{How to cite this article?}

Singh P, Kumar R, Gontia J, Singh DP, Gupta SB. A study of prevalence of anisometropia and associated amblyopia in patients with refractive error. Int J Med Res Rev 2015;3(5):514-519. doi: 10.17511/ijmrr.2015.i5.099. 